\title{
THE CASE FOR A COUPLED USER-ORIENTED PROCESS (RE)DESIGN AND INFORMATION SYSTEMS DEVELOPMENT
}

\author{
Maja Ćukušić ${ }^{1}$
}

DOI: https://doi.org/10.31410/ITEMA.S.P.2020.15

\begin{abstract}
The paper synthesises studies of two specific conceptual models from a rather wide area of user-oriented process (re)design and the development of related, modern information systems based on smart technologies. Further, it proposes a new approach for coupling (1) a methodology for convergent customer experience management and business process management, with (2) a framework for user-oriented data-driven information systems development. It also analyses the implications and conditions for its implementation in private and public organisations.
\end{abstract}

Keywords: User-oriented, Process redesign, Data-driven development, Information systems.

\section{INTRODUCTION}

7 he motivation for the research on the topic of user-centric process and information system (re)design stems from the rapid development of smart technologies and growing interest in digital transformation. In particular, the importance of big data technologies has been recognised for digital transformation and the creation of sustainable societies (Pappas, 2018). There is a growing number of studies in this regard; for example, on September $21^{\text {st, }}$ 2020, there are over 51.700 papers in the Google Scholar database (excluding citations and patents) on the topic "digital transformation". Out of these, over 1.100 acknowledge the shift towards "user-centric" processes and solutions (Google Scholar, 2020). In line with the trend, a research group at the University of Split was set up in 2017 with the aim to study different phenomena in a rather wide area of the user-oriented process (re)design and the development of related, modern information systems based on smart technologies. To date, the group has conducted several studies in this area as a part of the research project titled "User-oriented process (re)design and information systems modelling - a case of smart city services" (SmartCity.efst.hr, n.d.).

In reporting the progress of a scientific project and synthesising the research on the topic to date, several relevant studies have been published (available in Croatian scientific bibliography, n.d.). For this paper, two studies are important in particular, one proposing a novel methodology for convergent Customer eXperience Management (CXM) and Business Process Management (BPM) (Pavlić \& Ćukušić, 2019b) and the other one describing and evaluating a framework for user-oriented data-driven information systems development (Mijač, Jadrić \& Ćukušić, 2019). This paper seeks to identify the potential of combining the two concepts in digital transformation projects and, in one particular case, prerequisites for the implementation of the new, combined approach.

1 University of Split, Faculty of Economics, Business and Tourism, Cvite Fiskovića 5, 21000 Split, Croatia 
The structure of the paper is as follows: Section 2 presents the theoretical background of the study and the two concepts in more detail. Section 3 describes the procedure and the potential of combining the concepts, while Section 4 explores the benefits and conditions for the implementation of the approach. Section 5 concludes the paper and presents the limitations of the study.

\section{THEORETICAL GROUNDING}

Two trends that informed the decisions in a broader research study within the project: the usercentric view and emphasis on digital transformation in modern organisations have already been pinpointed in the introductory part of the paper. Specific research questions that led to the development of the methodology for convergent CXM and BPM and the framework for useroriented data-driven information systems development, i.e. the motivation for proposing the new approach is described hereinafter.

New research directions in the field of digital transformation: BPM and CX convergence Given the current level of maturity BPM, there are many challenges and research directions that stem from the convergence trend of two seemingly contradictory concepts: BPM - usually oriented towards improving internal processes, and CXM - bringing the external perspective of a customer into the organisation. Well-known marketing concepts, user/customer perspective, and customer journey mapping are experiencing a real revolution with the advent of new technologies (De Keyser et al., 2015), outlining the transformation of CX through, for example, the Internet of Things (IoT), Virtual Reality (VR), virtual assistants, chatbots and other (Hoyer et al., 2020), also leading to the development of new frameworks (e.g. Nasution et al., 2014) and popular call-to-action/research (Verhoef et al., 2009, Lemon \& Verhoef, 2016). Swift technological development (specifically - in terms of "smart" devices) is manifested, among other things, through the development of new methods and tools for collecting, storing, and processing user data in real-time. In this regard, and due to the abundance of objective user-related data and increased connectivity, researchers explore the advantages of linking two dominant approaches to analysis and process optimisation - an internal-oriented approach such as BPM and a more modern, user-oriented concept of managing user experience (Trkman et al., 2015), for example, through customer journey mapping (CJM) (Misiak, 2018), i.e. Customer eXperience (CX). The prospects and implications of business process analysis and optimisation when using the BPM-CX convergent approach, in comparison with the traditional BPM approach, have been presented elsewhere (Pavlić \& Ćukušić, 2019a, Pavlić \& Ćukušić, 2019b).

\section{Smart technologies for user-oriented and data-driven information systems development}

Smart devices enable a better understanding of customer needs (Hoyer et al., 2020), bringing customer-facing teams a step closer to collecting and understanding user needs as inputs for designing internal business processes and the development of related information systems. Nowadays the use of sensors and mobile applications is being investigated (as e.g. Petsani et al., 2020) to gain insights into user behaviour patterns that would lead to a better definition of user needs and requirements, and massive amounts of data are being analysed in the context of mapping user experiences. The results become the basis for the user-oriented information systems development (Mijač, Jadrić \& Ćukušić, 2018b) demonstrating the value and the potential of new technologies in the context of collecting, describing, and understanding user needs and user-oriented information system/service design. The approach to designing and developing information systems and related services under the principles of User-Centred Design (UCD) (Zimmermann \& Grötzbach, 2007) thus shifts towards experimenting with the 
use of smart devices for data collecting and Data-Driven Development (DDD) (Holmström Olsson \& Bosch, 2019), in particular. In this regard, relevant research questions focus on the effects of the technology development (specifically the development of smart devices and IoT) on the expectations of IS users on the one hand, and the possibilities to customise these systems to the users on the other hand. The value of collecting and storing user data and data generated by processes in which users participate to improve the overall user experience has been presented elsewhere (Mijač, Jadrić \& Ćukušić, 2018a, Mijač, Jadrić \& Ćukušić, 2018b).

\section{COUPLING USER-ORIENTED PROCESS (RE)DESIGN AND IMPLEMENTATION WITH DATA-DRIVEN INFORMATION SYSTEMS DEVELOPMENT}

The advancement in the development of user/customer journey mapping has been expedited by the development of new methods and tools for collecting and storing user data and their satisfaction in real-time: wearable devices, object tracking sensors, mobile applications, eyetracking tools, among others, follow and record every aspect of users' experience, while the analysis and value-extraction from the recorded data become possible with the maturity of big data technologies (Martin, 2016). Organisations thus gain valuable insights into behaviour patterns that consequently inform strategic and operational decisions; examples include targeted advertising, but also product development and process improvement (Kopanakis, 2018). Specifically, collecting and analysing real-user behaviour and needs become foundational for (re)designing internal business processes and developing user-oriented information systems, i.e. information on the experience and perspectives of users as well as the weak points (usually defined in the scope of CJM analyses) are essential inputs for organisations' business process improvement/automation (Vanwersch et al., 2015). Multifunctional teams (made up of marketing experts, development engineers, process owners, and more) are formed accordingly to make the user-oriented and data-driven development strategies a reality. However, even with the growing popularity of data-driven development and emerging frameworks, related efforts can fail due to competing interests and department KPIs, different methodologies employed by professionals coming from marketing, software engineering, BPM, and other backgrounds.

\section{Methodology for convergent BPM and CXM}

The implications of the BPM-CXM convergent approach, compared to the traditional BPM approach, have been a continuing research interest of a doctoral student and long-time BPM consultant, D. Pavlić (2020). Starting from a well-established BPM lifecycle model (Dumas et al., 2018), or a continuous cycle comprising six distinct phases, he describes an enhanced version that takes into account customer perspective throughout the lifecycle. Specifically (ibid, p. 23): (i) process identification, (ii) process discovery (also called as-is process modelling), (iii) process analysis, (iv) process redesign (also called process improvement), (v) process implementation, and (vi) process monitoring thus become (i) process and customer experience identification (resulting in process and customer experience architecture), (ii) process and customer experience discovery (including as-is process modelling and as-is customer journey mapping), (iii) process and customer experience analysis (resulting in insights from both perspectives), (iv) process and customer experience redesign (resulting in improvements reflected in to-be process models and to-be customer journey maps), (v) process implementation, and (vi) process and customer experience monitoring and control. In 2019 and 2020, the convergence concept has been endorsed and evaluated with experts, and a set of guidelines have been proposed to demonstrate and operationalise it (Pavlić \& Ćukušić, 2019b). 
In addition to the scientific relevance of the topic, given the popularity and significance of business transformation projects and BPM and CXM tools, wider acknowledgment and adoption of the new approach is sought and is currently being explored and identified in an international study. The methodology has also been piloted in a (digital) business transformation project in a private organisation, with results still to be reported. The use of BPM-CXM convergence approach, among other advantages, leads to more successful analysis and optimisation of business processes compared to the traditional BPM approach as an ongoing study seeks to confirm.

While the methodology facilitates an integrated analysis of customer experience and internal business processes and reflects the way customer experience can be perceived and analysed through the whole BPM lifecycle, one particular phase - process implementation seemingly overlooks the customer perspective. In the proposed approach, this particular phase was not explicitly considered/labelled as taking into account customer perspective, as it can be argued that the move from the as-is processes to the to-be process reflects the customer perspective identified and recorded in previous phases, especially in the process redesign phase. Process implementation refers to process automation in a strict sense, or a broader sense to the development and deployment of new or improvements of existing IT systems that support tobe processes (Dumas et al., 2018:23). In case the transformation from conceptual process model into executable ones is not done using the Business Process Model and Notation (BPMN) standard (or any other complementary standard), it would be fitting and opportune to explore combining the methodology for BPM and CXM convergence with the relevant framework(s), considering the trends and importance of user-centred and data-driven strategies in the development of information systems (presented earlier in Section 2).

\section{Framework for user-oriented data-driven information systems development}

In an attempt to formulate a framework for the user data-driven information systems development, several studies and reports were produced within the MIS4SC project (SmartCity.efst.hr, n.d.) such as (i) report on current status and trends regarding user-oriented information system development (UCD/UDD vs. DDD), (ii) report on the potential of techniques and technologies for collecting and storing user data to improve user experience, (iii) report on problems, disadvantages, and prerequisites for data-driven development, and (iv) recommendations for the user-oriented information systems development. The latter report detailed out a framework developed and evaluated in consultation with experts (and published as Mijač, Jadrić \& Ćukušić, 2019). In that, the importance of using objective data, as opposed to soliciting user requirements based on user feedback and interviews, is emphasized.

Collecting objective user-related data is still predominantly based on Google Analytics reports, and there are still only a few studies presenting how objective data are used as a part of datadriven strategies and IS development decisions (see Svensson, Feldt \& Torkar, 2019).

The framework acknowledges standard phases of information systems development and draws on an iterative approach to system design (such as the Boehm's spiral model of IS development, cf. Boehm, 1988). Considering the growing emphasis on user experience, the proposed framework ensures user perspective throughout and promotes using the data-driven approach systematically. Specifically, it acknowledges that objective and passive data can be used effectively and frequently to eliminate critical errors and to improve the whole users' journey while interacting with the system. Figure 1 depicts the framework, where the initial phase consists of collecting users' specifications based on existing (usage) data. The information system development phase is then followed by a testing phase supported by the collected usage 
data. For that, metrics have to be defined in the development phase. Using the collected data is crucial in the redesigning phase. For redesign purposes, data can be taken from external (tools used for passive tracking) or internal sources (server logs produced by users and by the system itself). Consequently, taking into account usage patterns and objective data, different strategies for improving user experience could be devised and tested throughout the redesign process and repeated during the whole lifecycle. The framework is also aligned with agile development practices as it surmises small and incremental changes that could be a subject of several different sprints in agile development.

Figure 1. Framework for user-oriented data-driven information systems development

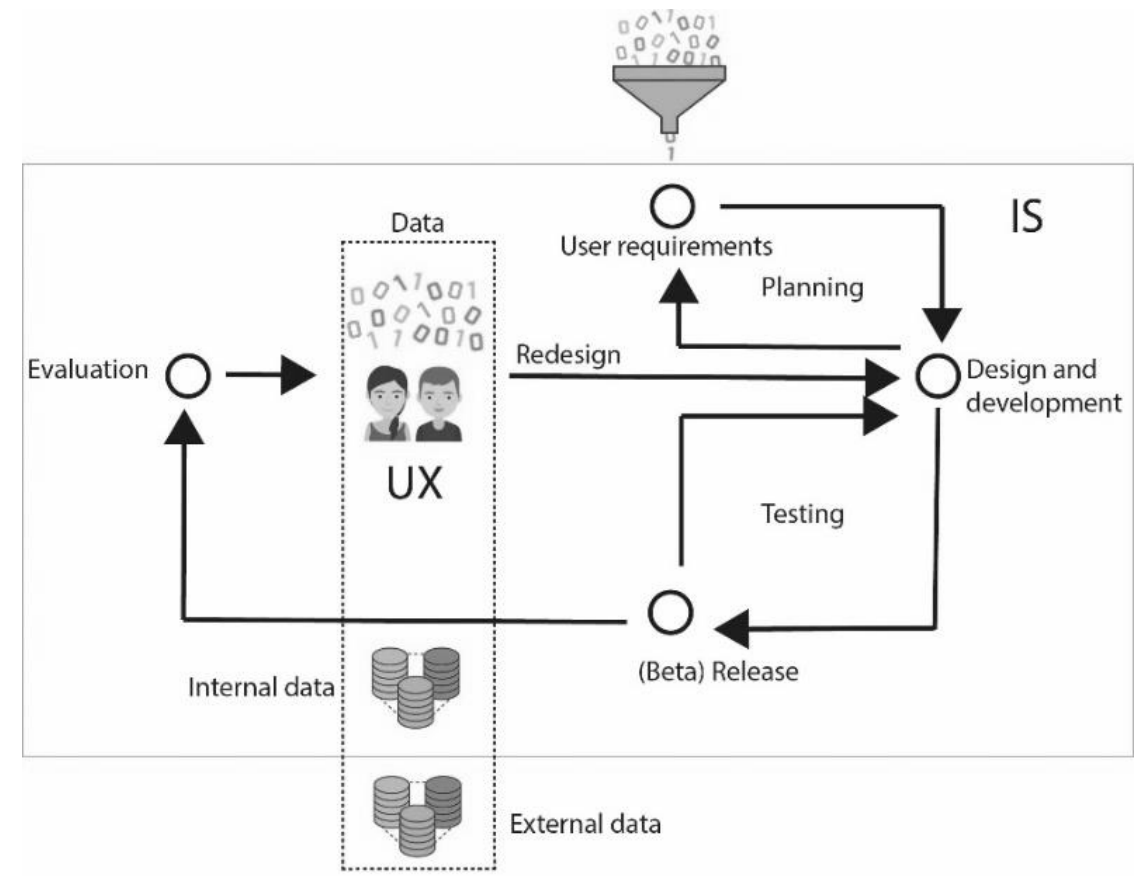

Source: Mijač, Jadrić \& Ćukušić, 2019

\section{POSTULATED IMPLICATIONS OF THE AMALGAMATED APPROACH FOR DIGITAL TRANSFORMATION PROJECTS}

The relevance and the shift towards "user-centric" processes and solutions in the context of digital transformation projects have been acknowledged in recent studies and reiterated in the introductory part of the paper. Technology has become a conduit for service and/or product transformation in public, and private organisations as processes are automated, and old technologies are being replaced. Following the years where decisions about implementing new technologies were unselective and made without a clear vision and identification of business needs, in recent times, researchers call for digital transformation efforts to be preceded by a diagnostic phase with in-depth input from customers (Tabrizi et al., 2019). Herein lies the key purpose of the approach presented in this paper. Specifically, using:

- the BPM methodology (BPM being at the core of digital transformation projects) that takes into account customer perspective throughout the whole lifecycle (BPM-CXM convergent approach), and in the process redesign and process implementation phases,

- supplementing it with the framework that advocates the use of objective, external and internal data to improve user experience, can result in significant benefits for organisations from the private and public sectors. 
Current research studies focusing on the implementation of user-oriented approaches bring about a broad list of advantages of engaging users in digital transformation projects, including both improvements of processes and information systems some of which have been presented already (see Section 1 and 2). The outcomes of the amalgamated approach for digital transformation projects presented herein are still to be analysed and evaluated following the implementation in real-life scenarios. At this stage, at the level of the conceptual model, among other things, it is posited that the new approach can result in two major positive outcomes:

- innovations in the planning and development practices of user-oriented information systems that will be triggered by getting a more objective and realistic overview of users (e.g. as in the case of developing data-driven web personas based on real user-data, and as presented in Mijač, Jadrić \& Ćukušić, 2018b), and

- more active participation and/or increased satisfaction of users of information systems (whether in the private or public sector), this being the ultimate aim of employing useroriented strategies.

However, the implementation and evaluation of the approach in real-life scenarios are still to be realised. In that, several conditions have to be fulfilled; whereby the main is ensuring that customer focus is the main driver for business/IT transformations. Even if that is the case, there are organisational settings that are still data-poor, lacking in procedures for collecting and storing user data. Throughout the last couple of years, while devising the new approach, several projects have been realised by the author of the paper that found that lack of systematic data management impairs user-oriented strategies significantly. Although to design a user-centric information system, lack of objective user data can be somewhat mitigated (as was done through experimentation, for example, in Čaljkušić Ivanović, 2018), it is essential to acknowledge and promote the importance of the objective and available data for the development of a user-oriented system.

\section{CONCLUSION}

Other than to promote and present two mechanisms developed within the framework of a scientific project, the purpose of the paper was to recollect how smart technologies can affect planning, designing, and managing user experience and how user data analysis and visualisation can contribute to the design of user-oriented information systems. Specific conditions and problems that emerge in the transition towards the user-oriented and data-driven development paradigm have been listed, and the path from traditional information systems development practices towards open, multidisciplinary user-oriented attempts has been outlined. It remains to detail out all the steps of the amalgamated approach for digital transformation projects that includes process and systems improvement and to systematically plan the evaluation of the approach in real scenarios.

\section{ACKNOWLEDGEMENT}

This work has been supported by the Croatian Science Foundation (grant number IRP-201705-7625).

\section{REFERENCES}

Boehm, B. W. (1988) A spiral model of software development and enhancement. Computer, 21(5), pp. 61-72. DOI: 10.1109/2.59 
Čaljkušić Ivanović, M. (2018) Metode za razvoj građanima orijentiranih informacijskih sustava: Diplomski rad. In Croatian. Available from https://urn.nsk.hr/urn:nbn:hr:124:359344

Croatian scientific bibliography (n.d.) The list of publications for Project HRZZ-UIP-2017-057625 https://www.bib.irb.hr/pretraga/?operators=and|HRZZ-UIP-2017-05$7625 \mid$ text|project

De Keyser, A., Lemon, K. N., Keiningham, T., \& Klaus, P. (2015), A Framework for Understanding and Managing the Customer Experience, MSI Working Paper No. 15-121. Cambridge, MA: Marketing Science Institute.

Dumas, M., La Rosa, M., Mendling, J., \& Reijers, H. A. (2018). Fundamentals of Business Process Management. Springer-Verlag Berlin Heidelberg. DOI: 10.1007/978-3-662$56509-4$

Google

Scholar

(2020), https://scholar.google.com/scholar?hl=hr\&as_sdt=1\%2C5\&as_vis=1\&q=\%22digital+tr ansformation $\% 22+$ and $+\% 22$ user-centric $\% 22$

Holmström Olsson H., Bosch J. (2019) Data Driven Development: Challenges in Online, Embedded and On-Premise Software. In: Franch X., Männistö T., Martínez-Fernández S. (eds) Product-Focused Software Process Improvement. PROFES 2019. Lecture Notes in Computer Science, Vol. 11915. Springer, Cham. DOI: 10.1007/978-3-030-35333936

Hoyer, W. D., Kroschke, M., Schmitt, B., Kraume, K., \& Shankar, V. (2020). Transforming the Customer Experience Through New Technologies. Journal of Interactive Marketing. 51, pp. 57-71. DOI: 10.1016/j.intmar.2020.04.001

Kopanakis, J. (2018) 5 Real-World Examples of How Brands are Using Big Data Analytics, Mentionlytics, available from https://www.mentionlytics.com/blog/5-real-worldexamples-of-how-brands-are-using-big-data-analytics/

Lemon, K. N., \& Verhoef, P. C. (2016). Understanding Customer Experience Throughout the Customer Journey. Journal of Marketing, 80(6), pp. 69-96. DOI: 10.1509/jm.15.0420

Martin, E. (2016) This is Why UX Design and Big Data Need Each Other, SmartData Collective. Available from https://www.smartdatacollective.com/why-ux-design-andbig-data-need-each-other/

Mijač, T., Jadrić, M. \& Ćukušić, M. (2018a) Evaluating the Potential of a Data-Driven Approach in Digital Service (Re)Design. In: Strahonja, V. \& Kirinić, V. (Eds.) Proceedings of the 29th Central European Conference on Information and Intelligent Systems. pp. 187-194.

Mijač, T., Jadrić, M. \& Ćukušić, M. (2018b) The potential and issues in data-driven development of web personas, 41st International Convention on Information and Communication Technology, Electronics and Microelectronics (MIPRO), Opatija, 2018, pp. 1237-1242, DOI: 10.23919/MIPRO.2018.8400224

Mijač, T., Jadrić, M. \& Ćukušić, M. (2019) In Search of a Framework for User- Oriented DataDriven Development of Information Systems. Economic and business review: for Central and South-Eastern Europe, 21 (3), pp. 439-465. DOI: 10.15458/ebr.89

Misiak, Z. (2018) How Can BPM and Customer Journey Mapping be Used Together? BMTrends, Available from https://www.bptrends.com/how-can-bpm-and-customerjourney-mapping-be-used-together

Nasution, R. A., Sembada, A. Y., Miliani, L., Resti, N. D. \& Prawono, D. A. (2014) The Customer Experience Framework as Baseline for Strategy and Implementation in Services Marketing. Procedia - Social and Behavioral Sciences, 148, pp. 254-261. DOI: 10.1016/j.sbspro.2014.07.041 
Pappas, I.O., Mikalef, P., Giannakos, M.N. et al. (2018) Big data and business analytics ecosystems: paving the way towards digital transformation and sustainable societies. Inf Syst E-Bus Manage 16, pp. 479-491. DOI: 10.1007/s10257-018-0377-z

Pavlić, D. \& Ćukušić, M. (2019a) Conceptualising the Convergence Model of Business Process Management and Customer Experience Management. In: Di Ciccio, C., Gabryelczyk, R., García-Bañuelos, L., Hernaus, T., Hull, R., Indihar Štemberger, M., Kö, A. \& Staples, M. (Eds.) Business Process Management: Blockchain and Central and Eastern Europe Forum. Cham, Springer International Publishing, pp. 328-332. DOI: 10.1007/978-3-03030429-4_24

Pavlić, D. \& Ćukušić, M. (2019b) Developing a Structured Approach to Converging Business Process Management and Customer Experience Management Initiatives. Lecture Notes in Business Information Processing, 369, pp. 151-166. DOI: 10.1007/978-3-030-351519_10.

Pavlić, D. (2020) Doctoral dissertation topic application; submitted to FEBT University of Split Faculty Council. Restricted access.

Petsani, D. et al. (2020) Creating a Feedback Loop Between Persona Development and User Research Towards Better Technology Acceptance. In Stephanidis, C., Marcus, A., Rosenzweig, E., Rau, P.-L. P., Moallem, A., \& Rauterberg, M. (Eds.). HCI International 2020 - Late Breaking Papers: User Experience Design and Case Studies. Lecture Notes in Computer Science. pp. 282-298. DOI: 10.1007/978-3-030-60114-0

SmartCity.efst.hr (n.d.) Website of the project "User-oriented process (re)design and information systems modelling - a case of smart city services". Available from http://smartcity.efst.hr

Svensson, R. B., Feldt, R. \& Torkar, R. (2019) The Unfulfilled Potential of Data-Driven Decision Making in Agile Software Development, In Kruchten, P., Fraser, S., and Coallier, F. (Eds) Agile Processes in Software Engineering and Extreme Programming. Cham: Springer International Publishing, pp. 69-85.

Tabrizi, B., Lam, E., Girard, K. \& Irvin, V. (2019) Digital Transformation Is Not About Technology Harvard Business Review, Available from https://hbr.org/2019/03/digitaltransformation-is-not-about-technology

Trkman, P., Mertens, W., Viaene, S. \& Gemmel, P. (2015) From business process management to customer process management. Business Process Management Journal, 21(2), pp. 250-266. DOI: 10.1108/bpmj-02-2014-0010

Vanwersch, R. J. B., Shahzad, K., Vanderfeesten, I., Vanhaecht, K., Grefen, P., Pintelon, L., ... Reijers, H. A. (2015) A Critical Evaluation and Framework of Business Process Improvement Methods. Business \& Information Systems Engineering, 58(1), pp. 43-53. DOI: $10.1007 / \mathrm{s} 12599-015-0417-\mathrm{x}$

Verhoef, P. C., Lemon, K. N., Parasuraman, A., Roggeveen, A., Tsiros, M., \& Schlesinger, L. A. (2009) Customer Experience Creation: Determinants, Dynamics and Management Strategies. Journal of Retailing, 85(1), pp. 31-41. DOI: 10.1016/j.jretai.2008.11.001

Zimmermann, D., Grötzbach, L. (2007) A Requirement Engineering Approach to User Centered Design. In: Jacko J.A. (Ed) Human-Computer Interaction. Interaction Design and Usability. HCI 2007. Lecture Notes in Computer Science, Vol 4550. Springer, Berlin, Heidelberg. DOI: 10.1007/978-3-540-73105-4_40 